\title{
Call for Papers: Learning From Practice Transformation
}

Ann Fam Med 2018;16:199. https://doi.org/10.1370/afm.2254.

$\mathrm{T}$

o help stimulate new knowledge relevant to supporting practice improvement and facilitated practice transformation, the Annals of Family

Medicine is issuing a call for manuscripts that address learning from practice transformation efforts. We seek papers on successes and failures that inform future efforts to improve practice and its system supports and partnerships. Accepted papers will be published in a 2019 supplement to the Annals made possible by the American Board of Family Medicine Support and Alignment Network funded under cooperative agreement by the Centers for Medicare \& Medicaid Services (Grant number: 1L1CMS331473-01-00).

Articles with the potential to assess outcomes, describe methods, or otherwise translate learning from these and other practice transformation models will be considered.

\section{BACKGROUND}

The Annals has published research and conceptual work on support for practice transformation. The Agency for Healthcare Research and Quality IMPaCT (Infrastructure for Maintaining Primary
Care Transformation) pilot built on mature primary care transformation models and supported the larger, 7-region research effort, EvidenceNOW: Advancing Heart Health in Primary Care. Similarly, the Centers for Medicare \& Medicaid Services is supporting the TCPI (Transforming Clinical Practice Initiative) demonstration project in all states. These programs represent the largest federal investment supporting practice transformation.

\section{SUBMISSION INSTRUCTIONS}

We welcome original research, methodology, and theory papers. Include a cover letter that states the manuscript is intended for the practice transformation supplement. All manuscripts are subject to the peer review process.

Manuscripts must be submitted through the Annals' eJournal Press system no later than August 31, 2018. "Instructions for Authors" and "Instructions for Submitting a Manuscript" are available on the "Author" page at http://www.AnnFamMed.org. 